\title{
Comunicação
}

[Communication]

\section{Níveis de anticorpos contra o vírus da cinomose canina e o parvovírus canino em cães não vacinados e vacinados}

[Antibodies levels against canine distemper virus and canine parvovirus in vaccinated and unvaccinated dogs]

\author{
R. Hass, J.M. Johann, C.F. Caetano, G. Fischer, G.D. Vargas, T. Vidor, S.O. Hübner* \\ Faculdade de Veterinária - UFPel \\ Caixa Postal 356 \\ 96010-900 - Pelotas, RS
}

O vírus da cinomose canina (CDV) e o parvovírus canino (CPV), agentes de enfermidades graves, são de ocorrência comum em áreas onde há animais suscetíveis. O CDV causa infecção aguda generalizada ou infecção crônica e persistente, localizada no sistema nervoso central. A infecção pelo $\mathrm{CDV}$ pode resultar em doença subclínica, digestiva ou respiratória, e, ainda, em uma forma sistêmica caracterizada por febre, rinite e problemas respiratórios freqüentemente associados a sinais de alterações no sistema nervoso central (Homem et al., 1999; Headley e Graça, 2000; Gama et al., 2007). O CPV é o mais importante agente etiológico de gastrenterite em cães (Castro et al., 2007). A gravidade da doença dependente da magnitude e da duração da viremia e, também, da taxa de renovação das células epiteliais intestinais, às quais infecta (Meunier et al., 1985).

A proteção contra as enfermidades causadas por esses vírus pode ser obtida mediante a utilização de vacinas que possuam adequada capacidade imunogênica (Ek-Kommonen et al., 1997; Jozwik et al., 2004) e gerem uma combinação de respostas imunológica humoral e celular (Greene, 1990). Há alta correlação entre os títulos de anticorpos e o nível de proteção e, devido a isso, a determinação dos níveis de anticorpos é uma medida amplamente utilizada como indicador de imunidade ao CDV e CPV, ao

Recebido em 28 de agosto de 2007

Aceito em 18 de janeiro de 2008

*Autor para correspondência (corresponding author)

E-mail: sohubner@yahoo.com.br fornecer informações a respeito da necessidade de vacinação ou revacinação de animais suscetíveis (Jozwik et al., 2004; Elia et al., 2005).

O presente trabalho teve como objetivos determinar os títulos de anticorpos contra o CDV e o CPV em cães não vacinados e vacinados e analisar a imunidade nesses animais. Além disso, avaliou-se associação entre determinados aspectos epidemiológicos (idade, acesso à rua e histórico de vacinação) e os níveis de anticorpos.

Foram examinadas 132 amostras de soro de cães de várias origens, levados ao Hospital Veterinário da Universidade Federal de Pelotas, RS, para atendimento clínico ou para receberem reforço vacinal, entre julho de 2005 e agosto de 2006. Os cães foram agrupados conforme a idade, local de habitação, condições clínicas e histórico vacinal. Tais informações foram obtidas mediante o preenchimento de um questionário submetido aos responsáveis pelos animais.

Os níveis de anticorpos específicos para o CDV foram pesquisados por meio da prova de soroneutralização (Appel e Robson, 1973). As amostras de soro foram incubadas com 100 doses infectantes para $50 \%$ dos cultivos celulares $\left(\right.$ DICC $\left._{50}\right)$ da amostra Lederle de CDV. Título de anticorpos igual ou maior que 20 foi considerado como indicador de imunidade contra o CDV (Krakowka et al., 1975). 
Para pesquisar os níveis de anticorpos contra o $\mathrm{CPV}$, as amostras de soro foram testadas por inibição da hemaglutinação (HI) (Garcia et al., 2000), utilizando-se a amostra de CPV Cornell (ATCC - VR2017). Títulos de anticorpos iguais ou maiores que 80 foram considerados como adequados para proteção (Pollock e Carmichael, 1982; Hoare et al., 1997).

Os resultados são apresentados nas Tab. 1 (CDV) e 2 (CPV). Anticorpos contra o CDV foram encontrados em 58,3\% (77/132) dos cães. A imunidade foi detectada em 40,1\% (53/132), sendo $33,3 \%(6 / 18)$ em animais de possuíam entre sete a 12 meses de idade; 43,6\% (24/55) nos de um a cinco anos; $40 \%(10 / 25)$ nos de seis anos; e em 59,1\% (13/22) nos de idade desconhecida. Não foram detectados animais com imunidade ao CDV nas faixas etárias de zero a seis meses de idade. Nos animais adultos (com idade acima de um ano), os níveis de anticorpos foram mais altos que nos cães com menos de um ano. Anticorpos contra o CDV foram detectados em um dos cinco cães com problemas gastrintestinais, nos três cães com sinais clínicos respiratórios e em um dos dois cães que apresentavam alterações neurológicas.

Em relação à moradia, foi observada tendência a maiores níveis de anticorpos nos animais com acesso à rua. Foram detectados anticorpos em títulos $\geq 20$ em $31,2 \%$ dos cães isolados, em $48 \%$ (24/50) dos que tinham acesso à rua e em 50\% $(6 / 12)$ dos que viviam sempre na rua. Independente do título, a positividade foi de $44,7 \%$ (17/38) em cães isolados, 68\% em cães com acesso à rua e 58,3\% em cães de rua. Possivelmente, os maiores níveis de anticorpos nos cães com acesso à rua, da mesma forma que nos adultos, indiquem a exposição natural ao CDV.

Tabela 1. Títulos de anticorpos contra o vírus da cinomose canina no soro de 132 cães, discriminados conforme a idade, tipo de moradia, condição clínica e histórico de vacinação

\begin{tabular}{|c|c|c|c|c|c|c|c|c|c|c|c|c|c|c|c|c|c|}
\hline \multirow[t]{2}{*}{ Título } & \multirow[t]{2}{*}{$\mathrm{N}^{\circ}$ cães } & \multicolumn{5}{|c|}{ Idade } & \multicolumn{4}{|c|}{ Habitat } & \multicolumn{4}{|c|}{$\begin{array}{l}\text { Condição } \\
\text { clínica }\end{array}$} & \multicolumn{3}{|c|}{$\begin{array}{l}\text { Histórico } \\
\text { vacinação }\end{array}$} \\
\hline & & 0 -6m & $7-12 \mathrm{~m}$ & $>1-5 a$ & $>6 \mathrm{a}$ & $\overline{\mathrm{ID}}$ & Isol & CR & Rua & $\mathrm{NI}$ & Sadio & GE & SR & $\mathrm{SN}$ & NV & Vac. & VD \\
\hline \multirow{2}{*}{$<10$} & 55 & 9 & 9 & 18 & 11 & 8 & 21 & 16 & 5 & 13 & 50 & 4 & - & 1 & 11 & 30 & 14 \\
\hline & $(41,7)$ & (75) & (50) & $(32,7)$ & (44) & $(36,3)$ & $(55,2)$ & (32) & $(41,6)$ & $(40,6)$ & $(40,1)$ & (80) & & (50) & (50) & $(37,5)$ & $(46,6)$ \\
\hline \multirow{2}{*}{10} & 24 & 3 & 3 & 13 & 4 & 1 & 7 & 10 & 1 & 6 & 22 & 1 & 1 & \multirow{2}{*}{0} & 4 & 18 & 2 \\
\hline & $(18,2)$ & (25) & $(16,6)$ & $(23,6)$ & (16) & $(4,5)$ & $(18,4)$ & (20) & $(8,3)$ & $(18,7)$ & (18) & (20) & $(33,3)$ & & $(18,2)$ & $(22,5)$ & $(6,6)$ \\
\hline \multirow{2}{*}{20} & 20 & , & 3 & 11 & 4 & 2 & 5 & 9 & 1 & 5 & 17 & \multirow{2}{*}{0} & 2 & 1 & 1 & 12 & 7 \\
\hline & $(15,2)$ & 0 & $(16,6)$ & (20) & (16) & $(9,1)$ & $(1,3)$ & (18) & $(8,3)$ & $(15,6)$ & $(13,9)$ & & $(66,6)$ & (50) & $(4,5)$ & (15) & $(23,3)$ \\
\hline \multirow{2}{*}{40} & 13 & 0 & 1 & 7 & 3 & 2 & 2 & 6 & 3 & 2 & 13 & \multirow{2}{*}{0} & \multirow{2}{*}{0} & \multirow{2}{*}{0} & 2 & 9 & 2 \\
\hline & $(9,8)$ & 0 & $(5,5)$ & $(12,7)$ & (12) & $(9,1)$ & $(5,2)$ & (12) & (25) & $(6,2)$ & $(10,6)$ & & & & $(9,1)$ & $(11,2)$ & $(6,6)$ \\
\hline \multirow{2}{*}{80} & 9 & & & 3 & 2 & 4 & 1 & 4 & 1 & 3 & 9 & \multirow{2}{*}{0} & \multirow{2}{*}{0} & \multirow{2}{*}{0} & 1 & 6 & 2 \\
\hline & $(6,8)$ & 0 & 0 & $(5,4)$ & (8) & $(18,2)$ & $(2,6)$ & (8) & $(8,3)$ & $(9,4)$ & $(7,4)$ & & & & $(4,5)$ & $(7,5)$ & $(6,6)$ \\
\hline \multirow{2}{*}{160} & 4 & 0 & 2 & 1 & 0 & 1 & 0 & 3 & 0 & 1 & 4 & \multirow[b]{2}{*}{ ( } & \multirow[b]{2}{*}{0} & \multirow{2}{*}{0} & 1 & 2 & 1 \\
\hline & (3) & 0 & $(11,1)$ & $(1,8)$ & 0 & $(4,5)$ & 0 & (6) & 0 & $(3,1)$ & $(3,3)$ & & & & $(4,5)$ & $(2,5)$ & $(3,3)$ \\
\hline \multirow{2}{*}{320} & 4 & 0 & 0 & 1 & 0 & 3 & 0 & 1 & 1 & 2 & 4 & \multirow[b]{2}{*}{ ( } & \multirow{2}{*}{0} & \multirow{2}{*}{0} & 1 & 1 & 2 \\
\hline & (3) & & & $(1,8)$ & & $(13,6)$ & & (2) & $(8,3)$ & $(6,2)$ & $(3,3)$ & & & & $(4,5)$ & $(1,2)$ & $(6,6)$ \\
\hline \multirow{2}{*}{640} & 2 & 0 & 0 & 0 & 1 & 1 & 2 & 0 & 0 & 0 & 2 & \multirow{2}{*}{0} & 0 & 0 & 1 & 1 & 0 \\
\hline & $(1,5)$ & 0 & 0 & 0 & (4) & $(4,5)$ & $(5,2)$ & 0 & 0 & 0 & $(1,6)$ & & 0 & 0 & $(4,5)$ & $(1,2)$ & 0 \\
\hline 21280 & 1 & 0 & 0 & 1 & 0 & 0 & 0 & 1 (1) & 0 & . & 1 & 0 & 0 & 0 & 0 & 1 & 0 \\
\hline .1280 & $(0,8)$ & 0 & 0 & $(1,8)$ & 0 & 0 & 0 & $1(2)$ & 0 & 0 & $(0,8)$ & 0 & 0 & 0 & 0 & $(1,2)$ & 0 \\
\hline Tut & 132 & 12 & 18 & 55 & 25 & 22 & 38 & 50 & 12 & 32 & 122 & 5 & 3 & 2 & 22 & 80 & 30 \\
\hline Toral & 132 & $(9,1)$ & $(13,6)$ & $(41,6)$ & $(18,9)$ & $(16,7)$ & $(28,8)$ & $(37,9)$ & $(9,1)$ & $(24,2)$ & $(92,4)$ & $(3,8)$ & $(2,3)$ & $(1,5)$ & $(16,6)$ & $(60,6)$ & $(22,7)$ \\
\hline
\end{tabular}

Entre parênteses: valores em porcentagem. m: meses; a: anos; ID: idade desconhecida; Isol: isolamento; CR: casa com acesso à rua; NI: habitat não informado; GE: gastrenterite; SR: sinais clínicos respiratórios; SN: sinais clínicos neurológicos; NV: não vacinado; Vac: vacinado; VD: vacinação desconhecida.

Dos 80 cães vacinados com pelo menos uma dose contra o CDV, $32(39,8 \%)$ apresentaram anticorpos em níveis protetores, o que indica uma resposta pós-vacinal. Contudo, tais níveis estavam presentes em $31,8 \%(7 / 22)$ dos não vacinados e em $46,6 \%$ (14/30) dos com histórico desconhecido sobre vacinação, o que sugere a ocorrência de imunização devido à exposição natural.

A maioria dos vacinados, 60,2\% (48/80), não apresentava anticorpos, ou apresentava título 
menor que 20. Várias razões podem explicar, ao menos parcialmente, a falha na indução de imunidade. Foi considerado como vacinado o cão que havia sido imunizado pelo menos uma vez, porém, se a vacinação foi realizada em um animal muito jovem, os anticorpos maternos podem ter interferido no desenvolvimento de uma imunidade ativa. Também pode ter sido realizada a imunização em animais com sistema imunológico debilitado. Além disso, deve-se considerar que o estoque e o manejo das vacinas podem influenciar sua eficácia, e que as vacinas podem apresentar diferentes capacidades imunogênicas. Contudo, diante do grande número de cães não reagentes ou com títulos de anticorpos considerados incompatíveis com a proteção, a qualidade das vacinas comerciais contra o CDV utilizadas no Brasil deve ser reavaliada. Em países onde a vacinação é sistemática, os estudos indicam que o título de anticorpos é adequado e esses se mantêm como tal até dois ou três anos após a última vacinação (Bohm et al., 2004; Jozwik et al., 2004; Mouzin et al., 2004).

Foram detectados anticorpos contra o CPV em 97,7\% (129/132) dos cães (Tab. 2). Níveis de anticorpos protetores foram detectados em $90,9 \%$
(120/132) da população examinada, sendo em $66,6 \%(6 / 9)$ dos cães com idade entre zero a seis meses e em 92,7\% (114/123) em animais com mais de seis meses. $O$ primeiro resultado significa que $34,4 \%$ dos cães jovens estavam suscetíveis ao desenvolvimento das enfermidades associadas a essa infecção no momento da análise. Os níveis de anticorpos foram mais altos em animais adultos, comparados aos jovens, provavelmente refletindo maior exposição a esse agente. Problemas gastrintestinais estavam presentes em 2,3\% (3/132) dos cães os quais apresentaram altos títulos de anticorpos contra o CPV ( $\geq 640)$.

Títulos de anticorpos $\geq 80$ contra o CPV foram detectados em 90,3\% (37/41) dos cães isolados, $91,5 \%$ (43/47) dos com acesso à rua e em $100 \%$ $(\mathrm{n}=10)$ dos cães que viviam na rua. A não diferença entre os níveis de anticorpos protetores conforme essas duas condições de habitação provavelmente deve-se a algumas características epidemiológicas do CPV, como sua excreção em grandes quantidades pelas fezes e, sobretudo, sua grande resistência no meio ambiente (Pratelli et al., 2001), que resultam em intensa e contínua exposição em todas as categorias avaliadas.

Tabela 2. Títulos de anticorpos contra o parvovírus canino no soro de 132 cães, discriminados conforme a idade, tipo de moradia, condição clínica e histórico de vacinação

\begin{tabular}{|c|c|c|c|c|c|c|c|c|c|c|c|c|c|c|c|c|c|}
\hline \multirow[t]{2}{*}{ Título } & \multirow{2}{*}{$\begin{array}{c}\mathrm{N}^{\circ} \\
\text { cães }\end{array}$} & \multicolumn{5}{|c|}{ Idade } & \multicolumn{3}{|c|}{ Habitat } & \multicolumn{5}{|c|}{$\begin{array}{c}\text { Condição } \\
\text { Clínica } \\
\end{array}$} & \multicolumn{3}{|c|}{$\begin{array}{c}\text { Histórico } \\
\text { vacinação }\end{array}$} \\
\hline & & $0-6 \mathrm{~m}$ & $7-12 \mathrm{~m}$ & $>1-5 a$ & $>6 \mathrm{a}$ & ID & Isol & $\mathrm{CR}$ & Rua & NI & Sadio & GE & SR & SN & NV & Vacinado & VD \\
\hline$<20$ & $\begin{array}{c}3 \\
(2,3)\end{array}$ & $\begin{array}{c}1 \\
(11,1)\end{array}$ & $\begin{array}{c}1 \\
(5,5)\end{array}$ & $\begin{array}{c}1 \\
(1,8)\end{array}$ & 0 & 0 & $\begin{array}{c}1 \\
(2,4)\end{array}$ & $\begin{array}{c}1 \\
(2,1)\end{array}$ & 0 & $\begin{array}{c}1 \\
(2,9)\end{array}$ & $\begin{array}{c}3 \\
(2,5)\end{array}$ & 0 & 0 & 0 & $\begin{array}{c}1 \\
(4,5)\end{array}$ & 0 & $\begin{array}{c}2 \\
(6,6)\end{array}$ \\
\hline 20 & $\begin{array}{c}1 \\
(0,8)\end{array}$ & 0 & 0 & 0 & $\begin{array}{c}1 \\
(3,4)\end{array}$ & 0 & 0 & 0 & 0 & $\begin{array}{c}1 \\
(2,9)\end{array}$ & 0 & 0 & 1 & 0 & 0 & 0 & $\begin{array}{c}1 \\
(3,3)\end{array}$ \\
\hline 40 & $\begin{array}{c}8 \\
(6,1)\end{array}$ & $\begin{array}{c}2 \\
(22,2)\end{array}$ & 0 & $\begin{array}{c}4 \\
(7,4)\end{array}$ & 0 & $\begin{array}{c}2 \\
(9,1)\end{array}$ & $\begin{array}{c}3 \\
(7,3)\end{array}$ & $\begin{array}{c}3 \\
(6,4)\end{array}$ & 0 & $\begin{array}{c}2 \\
(5,8)\end{array}$ & $\begin{array}{c}9 \\
(7,5)\end{array}$ & 0 & 0 & $\begin{array}{c}1 \\
(25)\end{array}$ & $\begin{array}{c}1 \\
(4,5)\end{array}$ & $\begin{array}{c}5 \\
(6,2)\end{array}$ & $\begin{array}{c}2 \\
(6,6)\end{array}$ \\
\hline 80 & $\begin{array}{c}8 \\
(6,1)\end{array}$ & $\begin{array}{c}1 \\
(11,1)\end{array}$ & 0 & $\begin{array}{c}2 \\
(3,7)\end{array}$ & $\begin{array}{c}2 \\
(6,9)\end{array}$ & $\begin{array}{c}3 \\
(13,6)\end{array}$ & $\begin{array}{c}3 \\
(7,3)\end{array}$ & $\begin{array}{c}1 \\
(2,1)\end{array}$ & $\begin{array}{c}1 \\
(10)\end{array}$ & $\begin{array}{c}3 \\
(8,8)\end{array}$ & $\begin{array}{c}6 \\
(5)\end{array}$ & 0 & 0 & 0 & 0 & $\begin{array}{c}5 \\
(6,2)\end{array}$ & $3(10)$ \\
\hline 160 & $\begin{array}{c}9 \\
(6,8)\end{array}$ & $\begin{array}{c}1 \\
(11,1)\end{array}$ & 0 & $\begin{array}{c}2 \\
(3,7)\end{array}$ & $\begin{array}{c}4 \\
(13,8)\end{array}$ & $\begin{array}{c}2 \\
(9,1)\end{array}$ & $\begin{array}{c}2 \\
(4,8)\end{array}$ & $\begin{array}{c}4 \\
(8,5)\end{array}$ & $\begin{array}{c}1 \\
(10)\end{array}$ & $\begin{array}{c}2 \\
(5,8)\end{array}$ & $\begin{array}{c}8 \\
(6,6)\end{array}$ & 0 & $\begin{array}{c}1 \\
(16,6)\end{array}$ & $\begin{array}{c}1 \\
(25)\end{array}$ & $\begin{array}{c}1 \\
(4,5)\end{array}$ & $\begin{array}{c}6 \\
(7,5)\end{array}$ & $\begin{array}{c}2 \\
(6,6)\end{array}$ \\
\hline 320 & $\begin{array}{c}21 \\
(15,9)\end{array}$ & $\begin{array}{c}1 \\
(11,1)\end{array}$ & $\begin{array}{c}2 \\
(11,1)\end{array}$ & $\begin{array}{c}8 \\
(14,8)\end{array}$ & $\begin{array}{c}8 \\
(27,6)\end{array}$ & $\begin{array}{c}2 \\
(9,1)\end{array}$ & $\begin{array}{c}5 \\
(12,2)\end{array}$ & $\begin{array}{c}6 \\
(12,7)\end{array}$ & $\begin{array}{c}2 \\
(20)\end{array}$ & $\begin{array}{c}8 \\
(23,5)\end{array}$ & $\begin{array}{c}19 \\
(15,8)\end{array}$ & 0 & $\begin{array}{c}1 \\
(16,6)\end{array}$ & $\begin{array}{c}1 \\
(25)\end{array}$ & $\begin{array}{c}4 \\
(18,2)\end{array}$ & $\begin{array}{c}14 \\
(17,5)\end{array}$ & $\begin{array}{c}4 \\
(13,3)\end{array}$ \\
\hline 640 & $\begin{array}{c}32 \\
(24,2)\end{array}$ & $\begin{array}{c}2 \\
(22,2)\end{array}$ & $\begin{array}{c}6 \\
(33,3)\end{array}$ & $\begin{array}{c}14 \\
(25,9)\end{array}$ & $\begin{array}{c}6 \\
(20,7)\end{array}$ & $\begin{array}{c}4 \\
(18,2)\end{array}$ & $\begin{array}{c}10 \\
(24,4)\end{array}$ & $\begin{array}{c}12 \\
(25,5)\end{array}$ & $\begin{array}{c}2 \\
(20)\end{array}$ & $\begin{array}{c}8 \\
(23,5)\end{array}$ & $\begin{array}{c}29 \\
(24,2)\end{array}$ & $\begin{array}{c}2 \\
(66,6)\end{array}$ & 0 & $\begin{array}{c}1 \\
(25)\end{array}$ & $\begin{array}{c}5 \\
(22,7)\end{array}$ & $\begin{array}{c}19 \\
(23,7)\end{array}$ & $\begin{array}{c}7 \\
(23,3)\end{array}$ \\
\hline 1280 & $\begin{array}{c}23 \\
(17,4)\end{array}$ & $\begin{array}{c}1 \\
(11,1)\end{array}$ & $\begin{array}{c}2 \\
(11,1)\end{array}$ & $\begin{array}{c}7 \\
(12,9)\end{array}$ & $\begin{array}{c}7 \\
(24,1)\end{array}$ & $\begin{array}{c}6 \\
(27,3)\end{array}$ & $\begin{array}{c}6 \\
(14,6)\end{array}$ & $\begin{array}{c}9 \\
(19,1)\end{array}$ & $\begin{array}{c}3 \\
(30)\end{array}$ & $\begin{array}{c}5 \\
(14,7)\end{array}$ & $\begin{array}{c}22 \\
(18,3)\end{array}$ & 0 & $\begin{array}{c}1 \\
(16,6)\end{array}$ & 0 & $\begin{array}{c}6 \\
(27,3)\end{array}$ & $\begin{array}{c}12 \\
(15)\end{array}$ & $\begin{array}{c}5 \\
(16,6)\end{array}$ \\
\hline$? 2560$ & $\begin{array}{c}27 \\
(20,4)\end{array}$ & 0 & $\begin{array}{c}7 \\
(38,9)\end{array}$ & $\begin{array}{c}16 \\
(29,6)\end{array}$ & $\begin{array}{c}1 \\
(3,4)\end{array}$ & $\begin{array}{c}3 \\
(13,6)\end{array}$ & $\begin{array}{c}11 \\
(26,8)\end{array}$ & $\begin{array}{c}11 \\
(23,4)\end{array}$ & $\begin{array}{c}1 \\
(10)\end{array}$ & $\begin{array}{c}4 \\
(11,7)\end{array}$ & $\begin{array}{c}24 \\
(20)\end{array}$ & $\begin{array}{c}1 \\
(33,3)\end{array}$ & $\begin{array}{c}2 \\
(33,3)\end{array}$ & 0 & $\begin{array}{c}4 \\
(18,2)\end{array}$ & $\begin{array}{c}19 \\
(23,7)\end{array}$ & $\begin{array}{c}4 \\
(13,3)\end{array}$ \\
\hline Total & 132 & $\begin{array}{c}9 \\
(6,8)\end{array}$ & $\begin{array}{c}18 \\
(13,6)\end{array}$ & $\begin{array}{c}54 \\
(40,9)\end{array}$ & $\begin{array}{c}29 \\
(22)\end{array}$ & $\begin{array}{c}22 \\
(16,7)\end{array}$ & $\begin{array}{c}41 \\
(31,1)\end{array}$ & $\begin{array}{c}47 \\
(35,6)\end{array}$ & $\begin{array}{c}10 \\
(7,6)\end{array}$ & $\begin{array}{c}34 \\
(25,7)\end{array}$ & $\begin{array}{c}120 \\
(90,9)\end{array}$ & $\begin{array}{c}3 \\
(2,3)\end{array}$ & $\begin{array}{c}6 \\
(4,5)\end{array}$ & $\begin{array}{c}4 \\
(3)\end{array}$ & $\begin{array}{c}22 \\
(16,6)\end{array}$ & $\begin{array}{c}80 \\
(60,6)\end{array}$ & $\begin{array}{c}30 \\
(22,7)\end{array}$ \\
\hline
\end{tabular}

Entre parênteses: valores em porcentagem, m: meses; a: anos; ID: idade desconhecida; Isol: isolamento; CR: casa com acesso a rua; NI: habitat não informado; GE: gastrenterite; SR: sinais clínicos respiratórios; SN: sinais clínicos neurológicos; NV: não vacinado; VD: vacinação desconhecida. 
Dentre os cães vacinados contra o CPV 93,7\% $(75 / 80)$ apresentaram títulos de anticorpos $\geq 80$. Esse índice foi de 90,9\% (20/22) entre os não vacinados e 83,3\% (85/30) nos cães com histórico de vacinação desconhecido. A não diferença de imunidade entre esses dois grupos evidencia que a imunidade instalada se deve mais à re-exposições naturais que à vacinação. Altos títulos de anticorpos são característicos de exposições naturais ao CPV (Pratelli et al., 2001).

Considerando os baixos títulos de anticorpos contra o CDV na maioria dos cães deste estudo, pode-se deduzir da necessidade de implementação de um programa amplo e contínuo de vacinação, capaz de induzir adequada imunidade ao CDV, que atinja todas as faixas etárias. Contudo, a prática de vacinação contra o CPV parece ser altamente justificada e necessária somente em animais jovens, pois esses não apresentam anticorpos em níveis desejáveis para proteção e, portanto, são suscetíveis ao desenvolvimento de parvovirose canina.

Palavras-chave: cão, cinomose, parvovirose, anticorpo, imunidade

\begin{abstract}
Antibody titres to canine distemper virus (CDV) and canine parvovirus (CPV) were measured in 132 dogs: 80 had been vaccinated at least once, 22 had not been vaccinated, and 30 had unknown vaccination history. Serum antibody titers were measured by means of serum neutralization (CDV) or hemagglutination inhibition (CPV). Serum $C D V$ titers $\geq 20$ and serum $C P V$ titers $\geq 80$ were considered protective. Protective antibodies to CDV were present in $40.1 \%$ of the population: $39.8 \%$ of the vaccinated dogs, $31.8 \%$ unvaccinated, and in $46.6 \%$ of the dogs with unknown vaccination history. Protective antibodies to CPV were present in $90.9 \%$ of the dogs: $93.7 \%$ of the vaccinated dogs, $90.9 \%$ of the unvaccinated, and $83.3 \%$ of the dogs with unknown vaccination history.
\end{abstract}

Keywords: dog, canine distemper, canine parvovirus, antibodies, immunity

\section{REFERÊNCIAS BIBLIOGRÁFICAS}

APPEL, M.; ROBSON, D.S. A microneutralization test for canine distemper virus. Am. J. Vet. Res., v.34, p.1459-1463, 1973.

BOHM, M.; THOMPSON, H.; WEIR, A et al. Serum antibodies titres to canine parvovirus, adenovirus and distemper virus in dogs in the UK which had not been vaccinated for at least three years. Vet. Rec., v.154, p.457-463, 2004.

CASTRO, T.X.; MIRANDA, S.C.; LABARTHE, N.V. et al. Clinical and epidemiological aspects of canine parvovirus (CPV) enteritis in the State of Rio de Janeiro: 1995-2004. Arq. Bras. Med. Vet. Zootec., v.59, p.333-339, 2007.

EK-KOMMONEN， C.; SIHVONEN， L.; PEKKANEN, K. et al. Outbreak of canine distemper in vaccinated dogs in Finland. Vet. Rec., v.141, p.380-383, 1997.

ELIA, G.; CAVAlli, A.; CIRONE, F. et al. Antibody levels and protection to canine parvovirus type 2. J. Vet. Med. B., v.52, p.320322, 2005.

GAMA, F.G.V.; NISHIMORI, C.T.; SOBREIRA, M.R. et al. Evaluation of electrophoretic profile and albumin quota in the cerebrospinal fluid of dogs with distemper showing or not nervous signs. Arq. Bras. Med. Vet. Zootec., v.59, p.77-80, 2007.

GARCIA, R.C.N.C.; PINTO, A.M.V.; COSTA, A. P. et al. Canine parvovirus infection in puppies with gastroenteritis in Niterói, Rio de Janeiro, Brazil from 1995 to 1997. Braz. J. Vet. Res. Anim. Sci., v.37, p.132-135, 2000.

GREENE, C.E. Immunoprophylaxis and immunotherapy. In: GREENE, C.E. (Ed). Infectious diseases of the dog and cat. Philadelphia: W.B. Saunders, 1990. p.21-53.

HEADLEY, S.A.; GRAÇA, D.L. Canine distemper: epidemiological findings of 250 cases. Braz. J. Vet. Res. Anim. Sci., v.37, p.136140, 2000. 
HOARE, C.M.; DEBOUCK, P.; WISEMAN, A. Immunogenicity of a low-passage, high-titer modified live canine parvovirus vaccine in pups with maternally derived antibodies. Vaccine, v.15, p.273-275, 1997.

HOMEM, V.S.F.; MENDES, Y.G.; LINHARES, A.C. Gastrenterite canina - agentes virais nas fezes de cães diarréicos e não diarréicos. Arq. Bras. Med. Vet. Zootec., v.51, p.531-536, 1999.

JOZWIK, A.; FRYMUS, T.; MIZAK, B. et al. Antibody titres against canine distemper virus in vaccinated and unvaccinated dogs. J. Vet. Med. B., v.51, p.99-103, 2004.

KRAKOWKA, S.; OLSEN, R.; CONFER, A. et al. Serological response to canine distemper viral antigens in gnotobiotic dogs infected with canine distemper virus. J. Inf. Dis., v.132, p.384-392, 1975.

MEUNIER, P.C.; COOPER, B.J.; APPEL, M.J.G. et al. Pathogenesis of canine parvovirus enteritis: sequential virus distribution and passive immunization studies. Vet. Pathol., v.26, p.617624, 1985.

MOUZIN, D.E.; LORENZEN, M.J.; HAWORTH, J.D. et al. Duration of serologic response to five viral antigens in dogs. J. Am. Vet. Med. Assoc., v.224, p.55-60, 2004.

PRATELLI, A.; CAVALLI, A.; MARTELLA, V. et al. Canine parvovirus (CPV) vaccination: comparison of neutralizing antibody responses in pups after inoculation with CPV2 or CPV2b modified live virus vaccine. Clin. Diagn. Lab. Immunol., v.3, p.612-615, 2001.

POLLOCK, R.V.; CARMICHAEL, L.E. Maternally derived immunity to canine parvovirus infection: transfer, decline and interference with vaccination. J. Am. Vet. Med. Assoc., v.180, p.37-42, 1982.

RIMA, B.K.; DUFFY, N.; MITCHELL, W.J. et al. Correlation between humoral immune responses and presence of virus in the CNS in dogs experimentally infected with canine distemper virus. Arch. Virol., v.121, p.1-8, 1991. 